
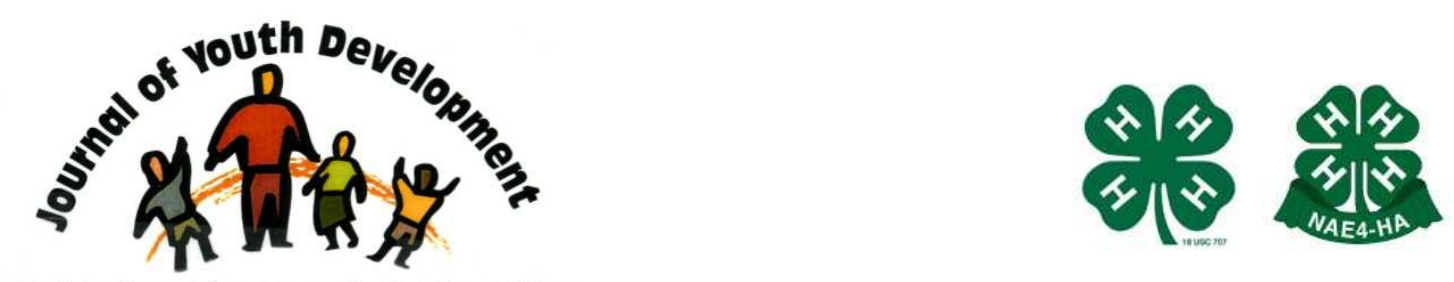

Bridging Research \& Practice

\title{
Diversity and Inclusion in Youth Development: What We Can Learn from Marginalized Young People
}

Stephen T. Russell

University of Arizona

strussell@arizona.edu

Kali Van Campen

University of Arizona 


\title{
JOURNAL OF YOUTH DEVELOPMENT \\ bridging research and practice

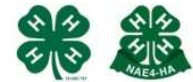

Volume 6, Number 3, Fall 2011

Article 110603FA006

\section{Diversity and Inclusion in Youth Development: What We Can Learn from Marginalized Young People}

\author{
Stephen T. Russell and Kali Van Campen \\ University of Arizona
}

\begin{abstract}
As we commemorate 100 years of youth development programs whose origins are traced to organizations founded in the United States, we consider key insights as well as strategies relevant for diversity and inclusion. Many of the large, mainstream youth development organizations and programs that were founded over a century ago now primarily serve youth in the "mainstream": youth from the middle classes, traditional families, and dominant cultural groups. A growing body of scholarship considers the positive development of youth who are marginalized due to their social class, ability, sexuality, citizenship status, race, ethnicity, or culture. We draw insights from studies of youth and families who are immigrants, or who are lesbian, gay, bisexual, and transgender (LGBT). These findings provide a vantage point for considering ways that contemporary youth development organizations might stretch the margins, or adapt their practices, in order to reach and include all youth.
\end{abstract}

\section{Introduction}

As we commemorate 100 years of youth development programs and practices whose origins are traced largely to organizations founded in the United States, we observe several contradictions or tensions in the field. There have been profound changes in the daily lives of youth and adolescents during the last century-demographic, social, economic, political, and technological-that have resulted in a youth population that is increasingly diverse in personal and family characteristics as well as life experiences. Yet many youth development organizations and programs that were founded over a century ago primarily serve youth in the mainstream: youth from the middle classes, from traditional families, and from dominant cultural groups. Although a number of programs were and still are designed to serve marginalized youth, in many mainstream programs and many communities youth at the margins continue to be absent or left out-whether intentionally or due to structural conditions or processes that emerged over a century of institutionalization. Notably, in some communities 
new organizations and programs have emerged to respond to the needs of youth on the fringes of a rapidly changing society.

Scholarship on positive youth development has begun to consider the needs of youth who are marginalized due to their social class, ability, sexuality, citizenship status, race, ethnicity, or culture. We use the term "marginalized" to denote the ways that some young people are pushed to the margins; the term emphasizes the social processes that render youth marginal, rather than focusing on deficits based in the person (i.e., defining youth as "at risk" or "vulnerable"). We highlight several areas of knowledge that have grown out of studies of youth and families who are immigrants, or who are lesbian, gay, bisexual, and transgender (LGBT). These findings provide a vantage point for considering ways that contemporary youth development organizations might stretch the margins, or adapt their practices, in order to reach and include all youth.

In this article we consider recent research on immigrant and lesbian, gay, bisexual, and transgender (LGBT) youth that we argue might inform current youth development programming, practice, and thinking. These young people grow up, as does everyone, in the mainstream-but their experiences often exist outside of it. That is, their identities and experiences do not always align with those of the dominant culture (whether defined as U.S.born, European-American, or heterosexual). Research in the past decade about the lives of immigrant and LGBT youth can offer insights about the possibilities of positive youth development for young people who may not be in the mainstream. In some youth organizations, marginalized youth are absent or invisible; in contrast, other youth organizations specifically serve marginalized youth. Our review is relevant in both cases by pointing to pertinent lessons regarding diversity and inclusion for all contemporary youth organizations.

\section{Historical Perspectives}

In the last 100 years, the contexts of youth in the United States have undergone profound change. The impact of industrialization, starting in the mid- $19^{\text {th }}$ century, created new patterns of work, education, and family life, which changed the role that young people played in society and ultimately led to the recognition of a new stage in the life course: adolescence. New employment opportunities led to dramatic migrations from rural to urban settings, and brought immigrants from around the world. As a result, cities emerged with dense areas of people living in close proximity to each other. In agrarian society, many children participated as laborers on their parents' farms. As machines began to replace workers, one way to protect adult jobs was to remove adolescents from the work force. Another concern was that factory jobs required more sophisticated skills and thereby additional training. Thus, adolescence became viewed as a time of preparation for adulthood, in which compulsory schooling instead of work became the norm for young people. This perspective also led to the view of youth as less capable than adults and more in need of guidance, and child protectionists argued to keep children out of work to avoid harm (Modell \& Goodman, 1990).

Over time, these two trends-a decline in paid child labor and a rise in formal schooling-helped create a childhood culture with age-graded peer groups, norms, and rituals. Discretionary time emerged in the afternoons when, especially in urban neighborhoods, overcrowding led thousands of young people to explore the streets, enjoy a few hours of freedom, and possibly earn extra money. Concerned about the dangers of street life both in terms of potential injuries and exposure to immoral behavior, many adults responded by developing informal afterschool activities that would alleviate children's boredom and provide opportunities for organized play 
(Halpern, 2002). Others created youth organizations with structured activities to promote American citizenship (Strong \& Posner, 2010). Throughout the century, the purpose of these programs has evolved as they responded to political mandates, cultural changes, and the varying developmental needs of children.

The first community-based afterschool programs were developed in immigrant communities in urban areas around the country with various goals, including care and protection, especially of younger children; the creation of greater opportunities for play; the prevention of problems, especially crime and delinquency; cultivating vocational talents; the negotiation of sexual risks, particularly for girls; and the "Americanization" of immigrant families (Halpern, 2002). Many of these programs were originally informal boys' clubs that expanded into larger play areas and gymnasiums as more children showed up. As settlements appeared in the late 1880 s, they also began doing "boys' and girls' work" (p. 183), with churches and religious groups providing programs that served specific ethnic groups. Throughout the decades, these programs have changed course in response to the political climate and child health needs of the period.

Primarily run by volunteers, afterschool programs have eventually been recognized as a formal practice, but the field of community-based afterschool programs has never developed into one formal system of services.

Another type of afterschool support for youth that emerged in the mid-19 ${ }^{\text {th }}$ century was outreach programs, many of which were developed through Park and Recreation Departments (PARDs). These innovative programs sought to find ways to engage youth-also those living in high risk environments-who were not attracted to organized services (Bocarro \& Witt, 2002). Specifically, the programs were designed to engage "dangerous and threatening youth" in their own area, and involved individuals with labels such as "detached youth workers," "street workers," and "extension workers" (p. 68), who worked with small numbers of youth in informal, non-organized settings, usually on the street. While such programs have been demonstrated to reach racial and ethnic minority youth, they have historically suffered from instability because they are typically funded as temporary solutions, are not facility based, and have high staff attrition rates.

During the Progressive Era (1890-1920) a new group of institutions emerged as structured and formal youth organizations with the goal of developing productive youth who could become contributing members of society. These organizations emerged during a period when a group of White European social reformers sought to address what they perceived as the "degeneracy, effeminacy, and artificiality of modern American culture" (Strong \& Posner, 2010, p. 393). Some of the oldest youth development organizations, such as YMCA, YWCA, Boy Scouts, Camp Fire USA, and 4-H Clubs, were founded particularly in response to a growing view that young people were becoming potential problems. From their inception, these organizations shared a common goal to provide opportunities for youth "to be heard and supported in a changing social world" (Costello, Toles, Spielberger, \& Wynn, 2001, p. 207). The YMCA and YWCA, independent organizations, emerged to help youth who were already working and handling adult responsibilities. 4-H began as a way to provide agricultural education to youth, and provided opportunities for youth to become independent, responsible, and productive citizens. Youth organizations such as the Boy Scouts of America (BSA) and Camp Fire USA were formed to provide opportunities for youth of European descent to develop close relationships with nature through woodcraft and wilderness sports (Strong \& Posner, 2010).

Critical reviews of 150 years of youth development organizations point out that most community-based programs were geared toward youth of European descent (Halpern, 2002; 
Strong \& Posner, 2010). As such, the organizations did not actively exclude ethnic minority youth, but rather the programs were designed to emulate the dominant mainstream cultural values of U.S. society which were, and in many ways still are, largely guided by values endorsed by White, European-descent heterosexuals. Contemporary evidence from large, mainstream youth organizations indicates that ethnic minority youth are underrepresented, and, for example, more likely to drop out of the mainstream youth programs compared to White youth (Russell \& Heck, 2008). In recent years, due to growing awareness of this under-representation of youth of color, as well as charges of cultural appropriation and lawsuits alleging discrimination, many of these youth organizations are reexamining their goals, programs, and outreach strategies. To remain vital and relevant in the $21^{\text {st }}$ century, some have begun to reframe their practices to include hard-to-reach youth populations. For example, Camp Fire USA has become more culturally inclusive and encouraged participants to wear ceremonial garb based on their ethnic traditions. The BSA has launched an Hispanic Initiative to engage Latino youth in its sports program based on soccer and scouting (Boy Scouts of America, 2010; Strong \& Posner, 2010). However, scholars and practitioners recognize that much work still needs to be done to make full inclusion possible.

Thus, despite efforts of some youth development organizations to address the needs of youth of color, studies show that ethnic minority youth, including African American, Latino, and American Indian youth, have not participated in youth programs to the same degree as middleclass, European American youth (Villarruel, Moniero-Sieburth, Dunbar, \& Outley, 2005). These findings are unfortunate, given that ethnic minority youth are more likely to come from disadvantaged communities and tend to be at greater risk for negative health, academic, and developmental outcomes (Centers for Disease Control and Prevention, 2008; Hay, Cortson, Hollist, Altheimer, \& Schaible, 2007). Many have experienced prolonged poverty, discrimination, segregation, and disproportionate involvement with justice systems. These youth could greatly benefit from participating in programs geared toward their specific developmental needs.

A large body of literature documents the marginalization of LGBT youth in the context of peer groups at school (D'Augelli, Pilkington, \& Hershberger, 2002). However, there is little existing research that specifically documents the participation (or under-representation) of sexual minority youth or LGBT youth in youth programs. Regardless of a lack of research, the most obvious evidence of exclusion of sexual minority youth is the 2000 Supreme Court decision that allows the Boy Scouts of America (BSA) to establish exclusionary membership criteria that applies to youth or adults who are openly gay.

In summary, youth development programs began with the goal of reaching marginalized youth. A growing interest in educational and recreational opportunities for middle-class youth emerged with the social and economic changes of the $20^{\text {th }}$ century, resulting in institutionalization of youth programs within the mainstream, and ultimately leaving out many marginalized young people. Undoubtedly some efforts intentionally excluded youth at the margins (e.g., the BSA explicit exclusion of gay youth). Yet many mainstream programs unintentionally fail to authentically attract youth who are marginalized. Perhaps unknowingly, some institutions and programs do not attract or are not relevant for these youth. Below we consider recent studies of immigrant and LGBT youth in order to understand why and how some youth may not be attracted to, or may be rejected from, youth programs. 


\section{Immigrant Youth in the United States}

Even though the United States has always been a society of immigrants, immigration has emerged as a public and political issue at multiple points in history; this is certainly true during the last decade. After several decades of stable immigration in the late twentieth century, major shifts in immigration patterns have occurred in the United States and around the world (Russell, Crockett, \& Chao, 2010). Individuals and families from Latin America and Asia/Pacific Rim make up the largest groups of current immigrants in the United States. In spite of very different cultures and histories, these groups share some commonalities that shape family life and youth development. At the risk of stereotyping or making overly broad generalizations, we describe some of these commonalities below, but acknowledge that there is great variability in cultural beliefs and practices both within and between immigrant groups. We draw from several areas of research in order to illustrate broad cultural differences; we then consider the relevance and implications for positive youth development.

First, the dominant culture in the United States is an archetype of Western individualism. By this we mean that the culture of youth, families, and communities is rooted in deeply held beliefs about the importance of individual autonomy, self-sufficiency, and achievement. For youth in this context a fundamental goal is often the development of independence and autonomy: indeed this is the very definition of adulthood (Arnett, 2004). In sometimes stark contrast, the largest immigrant groups in the United States come from cultures rooted in collectivism. Values and beliefs give primacy to the social group (for example, the extended family network), and rather than emphasizing the independence of the individual, the individual is understood as interdependent. That is, the self is defined not as a singular entity, but rather in relationship with the key members of the social group. This interdependence plays out in family life in ways that surprise many European Americans: families are defined not as post-1950s "nuclear" families, but as networks of kin relationships that may include multiple generations and biological as well as extended ties. In the case of immigrants from some Asian cultures, the "family" may include ancestors. In many Latino/a families there are complex family relations ( $e$ / compadrazco) that include extended kin, godparents, and close family friends, with whom relationships are often defined in terms of age, birth order, and gender. In such a family network, youth development is experienced and understood within a web of interdependent relationships. For example, parental sacrifice is a major dimension of parenting and parentadolescent relationships (Chao \& Kaeochinda, 2010); although parental sacrifice is a universal characteristic, in emphasizing the development of a child's independence from parents, Western (United States origin) models often overlook the sacrifices and things parents give up for their children, and thus have not accounted for the possibility of interdependence in family and community life.

Second, the communication in collectivist cultures is often indirect, relying on shared understandings of social contexts. Whereas U.S. Western communication is typically direct and verbal, for many immigrant youth, communication in families and the broader society may be based in roles and duties that are understood and well-defined, and thus unstated. For example, Asian American youth report that, unlike popular media representations of U.S. families, parents may not say "I love you"; however, their love is unquestioned by youth-it is understood by virtue of the family relationship and does not have to be stated (Russell, Crockett, \& Chao, 2010).

A third cultural difference in many immigrant communities is the degree to which the faith community and the family serve as the major civic institutions. That is, "civic participation" is 
defined in the United States as engagement in the polity; in contrast, family life is "private." Yet for many immigrant communities, the family network may be embedded in the religious community, and this network is the polity. The distinctions between "private" and "public" life may not be meaningful in the same way for families from collectivist cultures. Thus, in traditional Latino families the rituals of family and community life revolve around intersections of faith and extended family which may define the community (Russell \& Romero, 2011). This cultural understanding of networks may explain differences in civic participation (Gregory et al., 2006). For example, studies show that Asian American parents are less involved at their children's schools; however, they are more involved in education planning and guidance with their children (Chao, 1996). Therefore, it is not that families are "uninvolved," but that they are involved in different ways and based on different principles of relationships and interactions.

The cultural differences that exist in current immigrant communities in the United States have several implications for youth development programs and practices in the contemporary United States, particularly in terms of how we reach out to immigrant youth. A fundamental implication is simply for youth professionals to understand how starkly different the assumptions about social relationships, communication styles with non-family elders or other same-age peers, and "participation" in youth programming may be for youth from non-European American cultural backgrounds.

One issue to consider is the degree to which we emphasize individual achievement (e.g., competition) compared to collective learning and collaborative success. How might our emphasis respond and reinforce Western cultural models and potentially alienate (or at least be unfamiliar for) youth from non-Western cultures? The role of individual competition in youth programs has been the subject of debate for years (Fetsch \& Yang, 2002). The traditional 4-H club, for example, is often a model of collaborative learning, and yet competitions at a county or state fair place the emphasis on individual achievement or personal success (although there are categories in some competitions for group or club submissions). Suggestions to shift focus in 4-H record-keeping from competition to the development of life skills (Diem \& Devitt, 2003) may, for example, be an opportunity to consider how life skills development might be accomplished collaboratively.

Another issue is the extent to which aspects of our programs "assume" knowledge and an understanding of history among youth and adult participants. Given the 100-year histories of so many U.S. youth organizations, have programs become subcultures that rely on assumed values and goals? Many of these organizations have long and rich histories that involve multiple generations of family ties to specific programs in the United States. How much do we assume that youth will simply know what to expect before they begin as participants? Further, many of the major U.S. youth programs (e.g., 4-H clubs; Scouts; Camp Fire) were designed based on a model of adult volunteer participation and leadership, and rely on this model to sustain the basic institution. Yet efforts have been ongoing to understand why Latino/a parents, for example, are under-represented among youth program adult volunteers. In a study designed to investigate this question, it was discovered that the term "leadership" did not resonate with many involved Latino/a adults: they did not view their community engagement as leading, but rather viewed their role as collectively supporting children in the community (Gregory et al., 2006). This study demonstrates that institutional organizations and structures, and assumptions about shared understandings of things as basic as "volunteering," may create barriers to inclusion for marginalized youth and their families. There are important implications for how we reach out to youth participants and adult volunteers, and for sustaining engagement and participation of diverse communities. 
Our point is not that current programs are on the wrong track. The issue does not have to be about individual versus collaborative success, or explicit versus implicit communication and goals. Rather, we might think carefully about how and where we currently place emphasis, and whether there are opportunities for extending or adding new models of reaching youth that might draw in and engage those that have been underrepresented as the population of the United States becomes increasingly ethnically and culturally diverse.

\section{Lesbian, Gay, Bisexual, and Transgender Youth}

LGBT youth have emerged in the last decade as a visible identity-based group among adolescents in the United States. Most youth development professionals-certainly those in midcareer or later-grew up at a time when "coming out" (disclosing an LGBT identity to others) simply did not happen in adolescence, but was something that occurred in young adulthood or later. Contemporary youth are among the first to come out as LGBT in large numbers. Because in prior generations people simply did not come out during the teenage years, their presence and visibility today has challenged many of the major institutions that guide the lives of adolescence. Families, schools, faith communities, and community-based or youth organizations have not had frameworks for understanding and incorporating LGBT youth (Russell, 2002).

The visibility of LGBT youth was prompted by a number of factors. The HIV/AIDS crisis made homosexuality publicly visible in ways that had been historically unprecedented. With this visibility came a growing LGBT social movement. In addition, early reports began to highlight apparently extreme levels of health and behavioral risk among gay youth (several of the early studies drew from community-based samples made of up adolescent gay boys). This attention prompted a growing body of research, particularly during the last decade, on the health and well-being of LGBT youth, research which showed dramatic health disparities for these young people (Saewyc, 2011). There is clear scientific consensus that LGBT youth are vulnerable compared to their heterosexual peers. More recent work has begun to examine and explore the possibilities of resilience for LGBT youth (Russell, 2005), and other work has examined the contexts of development for LGBT youth in order to better understand the origins and explanations for risk and resilience in their lives (Horn, Kosciw, \& Russell, 2009).

Attention to the role of prejudice and discrimination as the mechanism that undermines wellbeing for all youth has grown. For example, studies show that racial/ethnic discrimination is associated with mental health distress and compromised academic performance for ethnic minority students (e.g., Wong, Eccles, \& Sameroff, 2003), and a number of studies have shown that anti-LGBT harassment is a common experience for contemporary youth and that it is linked with significant health risks (Bontempo \& D'Augelli, 2002; D'Augelli, Pilkington \& Hershberger, 2002; Poteat \& Espelage, 2007). In most studies, the focus has been on the school setting, and the message is clear that peer harassment in schools is often pervasive, particularly for LGBT youth. Further, discriminatory or prejudicial experiences undermine not only the marginalized young person (i.e., the LGBT young person), but have been shown to have negative effects on youth who simply witness harassment (Rivers, Poteat, Noret, \& Ashurst, 2010), and thus create hostile school climates for all youth. We should assume that similar processes operate among youth and adults in youth programs (indeed, one professional has written about his personal experiences with homophobia in a youth program; Myers, 2008).

Given the undermining effects of prejudice, the minority stress model (Meyer, 2003) offers an explanation of the pathways through which prejudice influences well-being. In addition to 
routine stressors, marginalized people experience minority stress, or discriminatory experiences. Through these experiences LGBT people come to expect rejection or discrimination, and therefore may attempt to conceal their marginalized identities in order to avoid discrimination. These processes contribute to "internalized homophobia"—or beliefs that the societal stereotypes and negative attitudes about homosexuality and LGBT people are legitimate, resulting in negative feelings about themselves (Meyer, 2003). This model is important because it offers an explanation for multiple health disparities based on attention to interactions of social and cultural attitudes (homophobia), actual prejudice and discrimination experiences, and internalized processes that lead to undermined psychological well-being. The model also suggests that important intervening factors could interrupt the strong link between marginalization and negative outcomes: positive social supports and coping strategies ought to lessen the influence of discrimination and negative self-evaluation on adjustment. In fact, youth development programs are conceptualized as playing a potential buffering role between adversity in a youth's life and ultimate positive adjustment. Thus we can begin to conceptualize the buffering role of social supports in youth development programs for LGBT youth. Do youth programs provide strong interpersonal support for youth, regardless of a youth's marginal identity or status, but particularly for those who are marginalized? Do the relationships with peers, adult volunteers and professionals, and the content and context of youth development activities provide the needed buffers to support LGBT and other marginalized youth?

Explicit attention to LGBT youth in youth development program contexts has been limited. Because so much attention has focused on the experiences of LGBT youth at school, some research has been conducted on youth participation in school clubs such as gay-straight alliances (GSAs), which are clubs formed to provide support, education, or advocacy for promoting a positive school environment for all students regardless of sexual orientation or gender identity (Griffin, Lee, Waugh, \& Beyer, 2004). Several studies have shown that participation in these largely youth-led school clubs is associated with school and community connectedness and civic engagement (e.g., Russell, Toomey, Crockett, \& Laub, 2010). One study based on focus group discussions with high school GSA leaders examined how they experienced empowerment through GSAs; youth reported that being in the GSA gave them knowledge about LGBT issues and their rights as students, which was the basis for empowerment through its influence on them personally and on their relationships with others at school. Personally, the knowledge they gained was perceived as helping them develop their voice and feel good about themselves; their relationships with other students and teachers were affected because they felt that they could make a difference for others or leave a legacy at their school through participation in sustaining the GSA for students that would follow them. Together, these personal and relational changes were the basis for empowerment described by these GSA club leaders (Russell, Muraco, Subramaniam, \& Laub, 2009).

The results of youth participation in GSAs look in many ways like the results that are intended from youth development programs: youth gain important intellectual, psychological, and social developmental benefits from participation in youth programs (Eccles \& Gootman, 2002), and not surprisingly, we see similar results for GSAs. Through collaborative activities toward a common goal, youth develop life skills that are crucial for engaged citizenship.

GSAs exist because the world is typically unfriendly to LGBT youth, yet they are an interesting example of the ways that youth development strategies might be particularly relevant for marginalized youth. But what are the implications for mainstream programs designed to meet the needs of all youth? Obviously, prejudice or homophobia may exist in any organization: only through proactive critical reflection and discussion can we assure that we are conscious of and 
aware of the ways that heterosexism, sexism, racism, and other forms of oppression may operate through youth programs. But a clear question is: how accepting-and affirming-of LGBT youth are typical youth programs? And how might youth programs be proactive in dismantling even subtle ways that LGBT youth and others may be marginalized or unwelcome?

\section{Conclusion}

What began as afterschool programs for poor, unemployed youth of working parents grew into an informal system of multiple local, regional, national, and international institutions serving generations of children and youth. Since the beginning, efforts have always been made to reach marginalized youth, yet during the course of a century, a mainstream has emerged in the United States, one that reflects dominant cultures. The consequence is that some youth remain underrepresented and underserved in youth development programs. In this article we have drawn from recent studies of youth who are often marginal-immigrants and LGBT youth-in order to make the case that the explanation for marginalization is not in the youth, but in the culture of contemporary youth development programs. Based on this synthesis of prior research, we offer concrete suggestions for questions that youth development program professionals might ask themselves about their organizations or programs-questions that may yield new insights or vantage points for creating organizations that values diversity and inclusion for all youth (see Appendix A for question examples).

Based on our discussion we suggest two broad implications for contemporary youth development institutions or programs - first, our basic understanding of "youth," and second, the cultural or community relevance of youth development programs and program cultures. First, this work suggests that we need to question the very meaning and understanding of "youth." The notion of youth in relation to community has very different meanings if we understand youth as a project of developing independence from family (within community) versus a process of emerging into community. (We acknowledge that these are not necessarily opposing understandings for many youth or communities.) For youth development professionals, the tension lies in the need to understand a youth's individual needs while considering the broad network of family, social, and community relations and experiences that may define the needs for that young person.

The second implication has to do with the culture of youth development institutions and programs. Youth become marginal from the mainstream in ways that are often invisible because the mainstream appears "normal." However, if we consider dominant culture as a collection of peculiar norms and habits (habits that are only "normal" because they are dominant), we may begin to uncover and understand processes of marginalization. In doing so, the question is no longer "why aren't marginal youth present?" but "what is it about programs and institutions that enables marginalization?" These questions could lead to examination of the ways that persistent inequalities related to race and ethnicity, social class, or sexuality appear in youth programs, and ultimately how these inequalities might be dismantled.

In summary, we propose that a critical examination of the ways we think about and understand "youth" and the culture of youth development programs offers the possibility to address persistent inequalities in the field, and the potential to reach and include marginalized youth in new ways. Doing so could chart a new path for the field-one characterized not only by addressing the needs of youth most "at risk," or providing for youth in the mainstream, but through cultivating institutions and programs that work to truly include and meet the needs of all youth. 
Acknowledgement: The authors acknowledge support from the Fitch Nesbitt Endowment and the Frances McClelland Institute at the University of Arizona, and a grant from the Ford Foundation to the Crossroads Collaborative: Youth, Sexuality, Health, and Rights.

\section{References}

Arnett, J.J. (2004). Emerging adulthood: The winding road from late teens through the twenties. Oxford: Oxford University Press.

Bocarro, J., \& Witt, P.A. (2002). Reaching out/reaching in: The long term challenges and issues of outreach programs. Journal of Park and Recreation Administration, 20(3), 65-80.

Bontempo, D.E., \& D'Augelli, A.R. (2002). Effects of at-school victimization and sexual orientation on lesbian, gay, or bisexual youths' health risk behavior. Journal of Adolescent Health, 30(5), 364-374.

Boy Scouts of America. (BSA). (2010). Hispanic Initiative. Retrieved from http://www.scouting.org/HispanicInitiatives.aspx

Centers for Disease Control and Prevention. (2008). Healthy Youth! Division of Adolescent and School Health's Program-at-a-Glance. Retrieved from http://www.cdc.gov/HealthyYouth/about/healthyyouth.htm

Chao, R.K. (1996). Chinese and European American mothers' beliefs about the role of parenting in children's school success. Journal of Cross-Cultural Psychology, 27, 403-423.

Chao, R.K., \& Kaeochinda, K.F. (2010). Parental sacrifice and acceptance as distinct dimensions of parental support among Chinese and Filipino American adolescents. In S.T. Russell, L. Crockett, \& R.K. Chao (Eds.). Asian American parenting and parent-adolescent relationships (pp. 61-77). New York: Springer.

Costello, J., Toles, M., Spielberger, J., \& Wynn, J. (2001). How history, ideology, and structure shape the organizations that shape youth. In P.L. Benson \& K.J. Pittman (Eds.), Trends in youth development: Visions, realities, and challenges. Norwell, MA: Kluwer Academic Publishers.

D'Augelli, A.R., Pilkington, N.W., \& Hershberger, S.L. (2002). Incidence and mental health impact of sexual orientation victimization of lesbian, gay, and bisexual youths in high school. School Psychology Quarterly, 172), 148-167.

Diem, K.G., \& Devitt, A. (2003). Shifting the focus of 4-H record-keeping from competition and subject matter to youth development and life skills. Journal of Extension, 41(6), Retrieved from http://www.joe.org/joe/2003december/iw1.php

Eccles, J.S., \& Gootman, J.A. (2002). Community programs to promote youth development. Washington, DC: National Academy Press. 
Fetsch, R.J., \& Yang, R.K. (2002). The effect of competitive and cooperative learning preferences on children's self-perceptions: A comparison of 4-H and non-4-H members. Journal of Extension, 40(3), Retrieved from http://www.joe.org/joe/2002june/a5.php

Gregory, P., Camarillo, J., Campbell, D., Dasher, S., King, N., Mann, M., et al. (2006). Learning from Latino community efforts. Journal of Extension, 44(3), Retrieved from http://www.joe.org/joe/2006june/a3.php

Griffin, P., Lee, C., Waugh, J., \& Beyer, C. (2004). Describing roles that Gay-Straight Alliances play in schools: From individual support to social change. Journal of Gay \& Lesbian Issues in Education, 1(3), 7-22.

Halpern, R. (2002). A different kind of child development institution: The history of after-school programs for low-income children. Teachers College Record, 104(2), 178-211.

Hay, C., Fortson, E.N., Hollist, D.R., Altheimer, I., \& Schaible, L.M. (2007). Compounded risk: The implications for delinquency of coming from a poor family that lives in a poor community. Journal of Youth \& Adolescence, 36, 593-605.

Horn, S.S., Kosciw, J.G., \& Russell, S.T. (2009). New research on lesbian, gay, bisexual, and transgender youth: Studying lives in context. Journal of Youth and Adolescence. 38, 863-866.

Meyer, I.H. (2003). Prejudice, social stress, and mental health in lesbian, gay, and bisexual populations: Conceptual issues and research evidence. Psychological Bulletin, 129, 674-697.

Modell, J., \& Goodman, M. (1990). Historical perspectives. In S. Feldman \& G. Elliott (Eds.), At the threshold: The developing adolescent (pp. 93-122). Cambridge, MA: Harvard University Press.

Myers, J.D. (2008). Interacting with your gay and lesbian colleague. Journal of Extension, 46(4), Retrieved from http://www.joe.org/joe/2008august/comm1.php

Poteat, V.P., \& Espelage, D.L. (2007). Predicting psychosocial consequences of homophobic victimization in middle school students. Journal of Early Adolescence, 272), 175-191.

Rivers, I., Poteat, V.P., Noret, N., \& Ashurst, N. (2010). Observing bullying at school: The mental health implications of witness status. School Psychology Quarterly, 24(4), 211-223.

Russell, S.T. (2002). Queer in America: Sexual minority youth and citizenship. Applied Developmental Science, 6, 258-263.

Russell, S.T. (2005). Beyond risk: Resilience in the lives of sexual minority youth. Journal of Gay and Lesbian Issues in Education, 2(3), 5-18.

Russell, S.T., Crockett, L.J., \& Chao, R. (Eds.) (2010). Asian American parenting and parentadolescent relationships. For R. Levesque (Series Ed.), Advancing responsible adolescent development, New York: Springer.

Russell, S.T., \& Heck, K.E. (2008). Middle-school drop-out? Enrollment trends in the California 4-H Youth Development Program. Applied Developmental Science. 12, 1-9. 
Russell, S.T., Muraco, A., Subramaniam, A., \& Laub, C. (2009). Youth empowerment and high school Gay-Straight Alliances. Journal of Youth and Adolescence. 38, 891-903.

Russell, S.T., \& Romero, A. (2011). Sexual orientation and identity in Latina/o youth: Implications for mental health. In N. Cabrera, F. Villarruel, \& H.E. Fitzgerald, (Eds.), Latina/o child psychology and mental health (pp. 133-158), part of the Praeger series on Child Psychology and Mental Health: Cultural and Racial Perspectives, H.E. Fitzgerald \& S.A. Denham, (Eds.). Santa Barbara: Praeger.

Russell, S.T., Toomey, R., Crockett, J., \& Laub, C. (2010). LGBT student activism and civic engagement. In L. Sherrod, C. Flanagan, \& J. Torney-Purta (Eds.), Handbook of research on civic engagement in youth (pp. 471-494). Hoboken, NJ: John Wiley \& Sons, Inc.

Saewyc, E.M. (2011). Research on adolescent sexual orientation: Development, health disparities, stigma, and resilience. Journal of Research on Adolescence, 21(1), 256-272.

Strong, P.T., \& Posner, L. (2010). Selves in play: Sports, scouts, and American cultural citizenship. International Review for the Sociology of Sport, 45(3), 390-409.

Villarruel, F.A., Moniero-Sieburth, M., Dunbar, C., \& Outley, C.W. (2005). Dorothy, there is no yellow brick road: The paradox of community youth development approaches for Latino and African American urban youth. In L. Reed (Ed.), Organized activities as contexts of development: Extracurricular activities after-school and community programs (pp. 111-129). Mahwah, NJ: Lawrence Erlbaum Associates.

Wong, C.A., Eccles, J.S., \& Sameroff, A. (2003). The influence of ethnic discrimination and ethnic identification on African American adolescents' school and socioemotional adjustment. Journal of Personality, 71(6), 1197-1232.

(c) Copyright of Journal of Youth Development Bridging Research and Practice. Content may not be copied or emailed to multiple sites or posted to a listserv without copyright holder's express written permission. However, users may print, download or email articles for individual use. 


\section{Appendix A}

Text Box: Questions to ask ourselves regarding diversity and inclusion:

- In what ways do the family or cultural experiences of youth differ, and what implications do these differences have for our program? (How) Could we acknowledge and incorporate those differences as sources of unique strengths that youth bring to our program?

- Can we detect differences in communication styles among youth in our program, and account for those differences in the ways we that interact and structure activities?

- What is the relative emphasis on individual versus group achievement? (How) Could we structure our program to incorporate a range of individual and collective activities and goals?

- How much is the history of our program part of the culture of the program? (How) Could we emphasize the values that the history implies rather than the specific history?

- How can we acknowledge and value differences of culture and sexuality among youth in our program?

- (How) Do our programs provide interpersonal support for youth - particularly and explicitly for those who may be marginalized? (Are LGBT, immigrant, ethnic minority, or economically disadvantaged youth present and included?)

- Do we actively confront racism, sexism, and homophobia in our program? Do we foster understanding, awareness, and skills for youth to address prejudice and discrimination in its many forms?

(C) Copyright of Journal of Youth Development Bridging Research and Practice. Content may not be copied or emailed to multiple sites or posted to a listserv without copyright holder's express written permission. However, users may print, download or email articles for individual use. 